\title{
Liver transplant center in México with low-volume and excellent results
}

\author{
Mario Vilatobá1, Miguel Ángel Mercado², Alan Gabriel Contreras-Saldivar', Rafael Paulino Leal-Villalpando, \\ Jorge Zamudio-Bautista ${ }^{3}$, Ignacio García-Juárez and Armando Gamboa-Domínguez ${ }^{5}$ \\ ${ }^{1}$ Department of Transplantation; ${ }^{2}$ Direction of Surgery; ${ }^{3}$ Department of Anesthesiology; ${ }^{4}$ Department of Gastroenterology; ${ }^{5}$ Department of Pathology. \\ Instituto Nacional de Ciencias Médicas y Nutrición Salvador Zubirán, Mexico City, Mexico
}

\begin{abstract}
Background: Orthotopic liver transplantation $(O L T)$ is the treatment of choice for end-stage liver disease. Many studies show an inverse relationship between the number of procedures and operative mortality. Objective: The objective of the study is to show the results of our center and determine if it can have comparable results to high-volume centers. Method: This is a retrospective study which analyzed the information of patients with OLT at our institution from 1985 to December 31, 2012. Depending on the date of transplantation, the study was divided into three stages. Stage 1: from 1985 to 1999, Stage 2: from 2000 to 2007, and Stage 3: from 2008 to 2012. In the 1, 2, and 3 stage, 22, 37, and 56 OLTs were performed, respectively. Results: Perioperative mortality was significantly lower between Stage 3 versus Stage 1 and 2 (3.5\% vs. 50\% and 21.7\%, $p=0.001)$. Patient survival was also better at 1 and 5 years at Stage $3(94.4 \%, 87.8 \%)$ versus era $2(77.6 \%, 66.17 \%)$ and Stage $1(47 \%$ and 29\%) $(p=0.001)$. Conclusion: The present results of OLT at our program are excellent despite being a low-volume center.
\end{abstract}

KEY WORDS: Transplant. Liver. Results. Low-volume.

\section{Introduction}

Orthotopic liver transplantation (OLT) is the treatment of choice for end-stage acute or chronic liver failure, as well as for some types of tumors ${ }^{1}$. In spite of all the advances in surgery and perioperative care, OLT remains a complex procedure, with a high rate of complications and non-negligible mortality. Numerous studies have documented an inverse relationship between the number of complex surgical procedures and post-operative mortality, defined as death within the following 30-90 days after a surgical procedure ${ }^{2,3}$. Even studies conducted more than a decade ago show the same relationship ${ }^{4}$. In 1994, Hosenpud et al. ${ }^{5}$ analyzed survival depending on heart transplantations volume and found the risk for death to be $31.1 \%$ higher at 12 months post-transplantation in a center that performed $<9$ transplantations per year, in comparison with those that performed more than 9 . In the specific case of OLT, in 1999, Edwards et al. ${ }^{6}$ reported that mortality was lower at centers with more than 20 transplantations per year, in comparison with centers that performed $<20$. However, in more recent publications, following the use of the model for end-stage liver disease (MELD), it would appear that the results are not affected if more or $<20$ OLTs are performed per year ${ }^{7-11}$. On the other hand, the difference between a low-volume and a high-volume center has never been addressed. That is, no minimal number has ever been

\author{
Correspondence: \\ Mario Vilatobá \\ Avda. Vasco da Quiroga, 15 \\ Col. Belisario Dominguez \\ Seccion XVI, Del. Tlalpan \\ C. P. 14080 , Ciudad de Mexico, Mexico \\ E-mail: mvilatoba@ hotmail.com
}

Date of modified version reception: 06-09-2016

Date of acceptance: 08-09-2016

DOI: 10.24875/GMM.M17000022
Gac Med Mex. 2017;153:405-412

Contents available at PubMed www.gacetamedicademexico.com 
established as being prohibitive for the performance of this highly complex type of procedures.

In Mexico, in spite of liver cirrhosis being the second cause of death in the economically active population ${ }^{12}$, the number of OLTs that are performed per million inhabitants is one of the lowest in Latin America. From the year 2003 onward, it has plateaued at 100-150 transplantations per year in the entire country. Therefore, the number of transplantations carried out percenter is generally lower than 10 , which makes it difficult for any center that performs this procedure to become a high-volume center ${ }^{13}$.

The present study has the purpose to show the OLT results in our institute since its beginnings, and to try to determine if a low-volume center such as ours can have adequate results, comparable to those at high-volume centers of the USA and Europe.

\section{Method}

This was a retrospective study, where the information of patients who received a dead donor OLT at the Instituto Nacional de Ciencias Médicas y Nutrición Salvador Zubirán (INCMNSZ) in the period from 1985 to December 31, 2012, was analyzed, except in those whom received liver and kidney simultaneous transplantation or split liver transplantation. The collection of data was carried out from electronic and printed clinical records. From the year 2008 onward, the collection of data was prolective. Clinical and demographic variables were recorded both to describe the population and to assess group comparability by stages. Perioperative mortality and morbidity, and survival at 1,3 , and 5 years were regarded as main outcomes. We analyzed transoperative determining variables such as bleeding, surgical time, cold ischemia time (time since the graft was extracted and stored in the icebox until it was taken out for implantation), warm ischemia time (time since the organ is removed from the preservation solution to be implanted until it is reperfused), blood product requirements, and post-surgical evolution such as days of stay at the intensive therapy unit (ITU), hospital length of stay, and post-surgical complications.

Donors' demographic and clinical data are only available from the year 2008 onward. The statistical analysis was performed using the STATA 10.0 package.

The first reported descriptive analysis is global, with the purpose to show the experience at INCMNSZ. The second analysis was performed with the purpose to determine the program's evolution according to the number of procedures carried out, taking as time cutoff points those described in the next paragraph.

For comparative purposes, the study recipients were divided into three historical stages depending on the date they received the transplant: Stage 1, from 1985 to 1999; Stage 2, from 2000 to 2007; and Stage 3, from 2008 to 2012.

In the univariate analysis, quantitative data were reported as means or medians with their respective dispersion depending on distribution, and categorical variables were reported as absolute and relative frequencies.

The comparison of measurements for pre-transplantation clinical and demographic variables to test for population homogeneity in the groups was performed with analysis of variance (ANOVA).

Outcomes' bivariate analysis was carried out with hypothesis testing for the contrast of means in cases where significant difference was observed in the ANOVA. Survival of samples was estimated using the Kaplan-Meier method. Statistical significance was established at $p<0.05$.

\section{Results}

In total, 117 OLTs were carried out from 1985 to 2012. As special situations, liver-kidney transplantation was performed in one patient with end-stage kidney disease and one split liver transplantation, and these cases were therefore not considered in the analysis. Finally, data on 115 dead-donor OLTs performed in 112 patients were collected (this included 3 retransplantations).

At stages 1, 2, and 3, 22, 37, and 56 transplantations were performed, respectively. Clinical and demographic variables divided by stage, including the time on waiting list and the MELD score, are presented in table 1. We can observe how the time on waiting list drastically decreased at last stage (Stage 1: 365 days; Stage 2: 675 days; Stage 3: 80 days) thanks to the increase in the number of donors and the implementation of MELD to assign organs in 2008. We also can observe how MELD was increased between Stage 2 and 3 (14.5 vs. 18.8), indicating that more seriously ill patients were intervened at last stage, although the difference was not significant $(p=0.42)$. Overall, most common etiologies were hepatitis $C$ virus infection, autoimmune conditions (primary biliary cirrhosis and primary and autoimmune sclerosing cholangitis) and alcohol consumption and liver steatosis; there was no significant difference in etiology at different stages (Table 2). 
Table 1. Demographic variables and MELD divided by stages

\begin{tabular}{|c|c|c|c|c|}
\hline Variable & $\begin{array}{c}\text { Stage 1 } \\
(1985-1999) \\
n=22\end{array}$ & $\begin{array}{c}\text { Stage } 2 \\
(2000-2007) \\
n=37\end{array}$ & $\begin{array}{c}\text { Stage } 3 \\
(2008-2012) \\
n=56\end{array}$ & $p$ \\
\hline Days on waiting list* & $365(24-365)$ & 675 (325-1180) & $80(47-302)$ & 0.001 \\
\hline $\mathrm{Age}^{+}$ & $36.3 \pm 13.3$ & $45.27 \pm 11.69$ & $45.46 \pm 12.08$ & 0.01 \\
\hline Gender (\% males) & 38 & 51 & 51 & 0.54 \\
\hline $\mathrm{BMI}^{+}$ & $23.8 \pm 4.83$ & $25.35 \pm 4.14$ & $24.47 \pm 3.75$ & 0.40 \\
\hline MELD* & $18.4(6-40)$ & $14.5(6-38)$ & $18.8(7-40)$ & 0.42 \\
\hline
\end{tabular}

${ }^{*}$ Median (interquartile range).

${ }^{\dagger}$ Mean \pm standard deviation

BMI: body mass index; MELD: model for end-stage liver disease.

Perioperative period associated variables such as surgical time, cold and warm ischemia times, use of blood products, ITU and hospital length of stay, and perioperative mortality, among others, are summarized in table 3. Unfortunately, cold and warm ischemia times are not available for Stages 1 and 2. Surgical time, the use of blood products and bleeding, was statistically significantly lower at Stage 2 in comparison with Stages 1 and 3. However, reoperations, ITU length of stay, and perioperative mortality were significantly lower at Stage 3 in comparison with Stages 1 and 2.

Medical and surgical complications occurring in the (early and late) pre-operative period are summarized by stage in tables 4-6. A higher percentage of medical complications is observed at Stage 3 versus 2 (48\% vs. $43 \%$ ), in contrast with surgical complications, which were higher at Stages 1 and 2 than at Stage 3 (36.3\% and $48.6 \%$ vs. $21.4 \%$ ).

As for the seriousness of complications with the Clavien classification, we observed a higher number of I and II complications at Stage 3; however, serious complications (III-V) were more common at Stages 1 and 2 (Table 7).

Evolution in the use of immunosuppressants over time is depicted in figure 1, which shows that the most common immunosuppressant scheme was initially based on cyclosporine and azathioprine and that currently the most widely used is based on monoclonal antibodies, mycophenolate mofetil, and tacrolimus. Figure 2 shows recipients' survival at 1,3 , and 5 years divided by stage, where a survival statistically significant improvement in can be appreciated as stages advance.

\section{Donors}

Unfortunately, we had no data on Stage 1 and 2 donors; however, according to the INCMNSZ OLT protocol stipulations, only ideal donors based on the donor risk index were considered at Stage $2^{14}$. It's important mentioning that all performed transplants were from donors diagnosed with brain death with the heart still beating. Clinical and demographic characteristics from Stage 3 donors are summarized in table 8 . The purposes of this description are population-related, and no analysis of these data with regard to receivers' evolution and outcome was therefore performed.

\section{Discussion}

The present study shows the OLT outcomes at INCMNSZ since the first OLT in Mexico,,$^{15}$ until the year 2012. We decided to divide this period into 3 stages. We considered Stage 1 since the beginnings and until 1999 , when the procedure was performed sporadically; Stage 2, from the year 2000 to 2007 , because in spite of a multidisciplinary team being available since 2000 , there were never 10 or more transplantations performed per year at this stage; Stage 3 was, therefore, from 2008 to 2012. The year 2012 was established in order for transplant recipients to have at least 1 year of follow-up. Our program's evolution, from a pioneer center to the present day, has shown a big difference at last stage (2008 to 2012), where the majority of OLTs (56/117) were performed and with better results. This evolution of the program is reflected by the type of surgery, since at Stage 1, venovenous bypass was predominant (77\%), while at stages 2 and 3 , it was total exclusion (95\% and $98 \%$, respectively). Comparing stages 2 and 3 allows for us to know more clearly the improvement with regard to OLT number and outcomes in our center since there was exactly the same infrastructure and, since the year 2000, the procedure is performed exactly the same way. With 
Table 2. Etiology of patients who received OLT divided by stages

\begin{tabular}{lcccc}
\hline & $\begin{array}{c}\text { Stage } \mathbf{1} \\
\mathbf{n = 2 2} \\
\mathbf{n}(\%)\end{array}$ & $\begin{array}{c}\text { Stage } \mathbf{2} \\
\mathbf{n = 3 7} \\
\mathbf{n}(\%)\end{array}$ & $\begin{array}{c}\text { Stage } \mathbf{3} \\
\mathbf{n}=\mathbf{5 6} \\
\mathbf{n}(\%)\end{array}$ & $\mathbf{p}$ \\
\hline HCV & $5(22.72)$ & $11(29.72)$ & $23(41.07)$ & 0.247 \\
Autoimmune & $7(31.81)$ & $14(37.83)$ & $13(23.21)$ & 0.308 \\
Alcohol & $5(22.72)$ & $2(5.4)$ & $4(7.14)$ & 0.063 \\
NASH & 0 & 0 & $5(8.92)$ & NA \\
Other & $5(22.72)$ & $10(27.02)$ & $11(19.64)$ & 0.707 \\
\hline Autoimmune: primary biliary cholangitis, primary autoimmune hepatitis: NA: not applicable: NASH: non-alcoholic steatohepatitis: HCV: hepatitis C virus. &
\end{tabular}

Table 3. Perioperative variables divided by stages

\begin{tabular}{|c|c|c|c|c|}
\hline & $\begin{array}{c}\text { Stage } 1 \\
n=22\end{array}$ & $\begin{array}{c}\text { Stage } 2 \\
\mathrm{n}=37\end{array}$ & $\begin{array}{c}\text { Stage } 3 \\
n=56\end{array}$ & $p$ \\
\hline \multicolumn{5}{|l|}{ Type of transplantation } \\
\hline Bypass & 17 & - & - & \\
\hline Piggyback & - & 2 & 1 & \\
\hline Total exclusion & 4 & 35 & 55 & \\
\hline Heterotopic aux. & 1 & - & - & \\
\hline CIT h (IQR) & ND & ND & $9(5-12)$ & NA \\
\hline WIT min (IQR) & ND & ND & $55(30-75)$ & NA \\
\hline SxT h (IQR) & $10.6(6-17)$ & $6.5(4.5-9)$ & $7.2(4-13)$ & $<0.001$ \\
\hline PRBCs no. (IQR) & $16.8(4-57)$ & $9.5(3-48)$ & $11(2-33)$ & 0.017 \\
\hline FFP no. (IQR) & $13.3(2-34)$ & $4.6(2-18)$ & $9.9(2-28)$ & 0.001 \\
\hline Bleeding liters (IQR) & $5.7(0.9-20)$ & $3.9(1-12)$ & $6.4(1-24)$ & 0.058 \\
\hline ITU days (IQR) & $8.4(0-30)$ & $6.4(0-30)$ & $4.1(0-30)$ & 0.025 \\
\hline Inpatient floor days (IQR) & $13(0-62)$ & $10.9(0-45)$ & $11.4(0-60)$ & 0.730 \\
\hline \multicolumn{5}{|l|}{ Reinterventions } \\
\hline $\operatorname{ELAP}(\%)$ & $5(22.7)$ & $8(21.6)$ & $6(10.71)$ & 0.262 \\
\hline $\mathrm{BDB}(\%)$ & $1(4.5)$ & $3(8.1)$ & - & 0.108 \\
\hline Retransplantation (\%) & $2(9)$ & $1(2.7)$ & - & 0.077 \\
\hline Transoperative death (\%) & $4(18.1)$ & $2(5.5)$ & - & 0.005 \\
\hline Operative death (\%) & $7(31.8)$ & $6(16.2)$ & $2(3.5)$ & 0.003 \\
\hline
\end{tabular}

BDB: biliodigestive bypass; CIT: cold ischemia time; ELAP: exploratory laparotomy; FFP: fresh frozen plasma; IQR: interquartile range; ITU: intensive therapy unit; NA: not applicable; ND: no data; PRBCs: packed red blood cells; SxT: surgical time; WIT: warm ischemia time.

regard to the time on waiting list, it significantly decreased from stages 1-3 (365, 657, and 80 days, respectively; $p=0.0001$ ), thanks to increase in the number of donors and the assignment of organs through MELD. Previously, organ assignation for liver transplantation was made by means of the Child-Pugh classification, and 4 UNOS (United Network for Organ Sharing) stages were considered, 1A, 2A, 2B, and 3, where the time on waiting list was a highly important factor to choose the recipient. In the case of MELD, the most seriously ill patients are intervened and the time on waiting list is not a determining factor; therefore, the time on waiting list is lower at the MELD stage. In our center, MELD started being used in 2008 and, therefore, transplantation was performed in more seriously ill patients at Stage 3, although the difference was not statistically significant (Stage 2, $14.5 \%$ vs. Stage 3, $18.8 \% ; p=0.42$ ). With regard to perioperative variables, we observed that both surgical time and blood product use and bleeding occurrence were higher at Stage 3 than at Stage 2. At first glimpse, it would appear that there is no improvement in the results, but when we look at more important variables such as operative mortality $(3.5 \%$ vs. $21.7 \% ; p=0.001)$ and 
Table 4. Early medical complications divided by stages

\begin{tabular}{|c|c|c|c|c|}
\hline & $\begin{array}{c}\text { Stage } 1 \\
n=22\end{array}$ & $\begin{array}{c}\text { Stage } 2 \\
\mathrm{n}=37\end{array}$ & $\begin{array}{c}\text { Stage } 3 \\
n=56\end{array}$ & $p$ \\
\hline Total complications & 47 & 24 & 29 & 0.001 \\
\hline \multicolumn{5}{|l|}{ Early } \\
\hline Infections & 9 & 8 & 4 & 0.025 \\
\hline Acute rejection & 9 & 8 & 8 & 0.537 \\
\hline Acute renal failure & 9 & 5 & 5 & 0.002 \\
\hline Pulmonary complications & 7 & 0 & 5 & 0.049 \\
\hline Neurological & 2 & 1 & 5 & 0.407 \\
\hline Other & 11 & 2 & 2 & 0.001 \\
\hline
\end{tabular}

Table 5. Late medical complications divided by stages

\begin{tabular}{lcccc}
\hline & $\begin{array}{c}\text { Stage 1 } \\
\mathbf{n = 2 2}\end{array}$ & $\begin{array}{c}\text { Stage 2 } \\
\mathbf{n = 3 7}\end{array}$ & $\begin{array}{c}\text { Stage 3 } \\
\mathbf{n = 5 6}\end{array}$ & $\mathbf{p}$ \\
\hline Total complications & 7 & 21 & 9 & 0.001 \\
Diabetes mellitus & 0 & 4 & 2 & 0.945 \\
Systemic arterial hypertension & 1 & 3 & 2 & 0.621 \\
End-stage chronic renal failure & 1 & 1 & 0 & 0.614 \\
Oncologic & 0 & 3 & 0 & NA \\
Other & 5 & 10 & 5 & 0.060 \\
\hline NA: not applicable. & & & &
\end{tabular}

survival at 1 and 5 years ( $87.8 \%$ vs. $77.6 \%$ and $66.7 \%$; $\mathrm{p}=0.001$ ), we can appreciate an improvement in the results (Table 3). Medical complications were very similar between both stages, and surgical complications significantly decreased from Stage $2(48.6 \%)$ to Stage $3(21.4 \%)$. As for the report of complications by seriousness, a higher number of Grade I and II complications on the Clavien-Dindo classification are observed at Stage 3 than at Stage 2; we believe this higher number is due to the fact that patient perioperative information was prospectively collected at Stage 3, and this enables better capture of minor complications. However, when we observe Grade III to V complications, we find again a lower number at Stage 3. If we consider that, internationally, operative mortality is $5 \%$ and 1 -year survival $86 \%$, the results in our institute at the latter stage are better than those internationally reported, even at high-volume centers, and are much better than those separately reported by the majority of national centers ${ }^{16-20}$.

OLT is a highly complex procedure that involves multiple critical factors both from the donor and the receiver, and it requires an experienced multidisciplinary team. Although high-volume centers have been shown
Table 6. Surgical complications divided by stage

\begin{tabular}{lcccc}
\hline & $\begin{array}{c}\text { Stage 1 } \\
\mathbf{n = 2 2}\end{array}$ & $\begin{array}{c}\text { Stage 2 } \\
\mathbf{n = 3 6}\end{array}$ & $\begin{array}{c}\text { Stage 3 } \\
\mathbf{n = 5 6}\end{array}$ & $\mathbf{p}$ \\
\hline Total complications & 11 & 18 & 15 & 0.002 \\
Surgical site hemorrhage & 7 & 3 & 3 & 0.013 \\
Biliary complications & 1 & 7 & 8 & 0.302 \\
Vascular complications & 0 & 2 & 4 & 0.539 \\
Graft primary failure & 2 & 3 & 0 & 0.208 \\
Other & 1 & 3 & 0 & 0.108 \\
\hline
\end{tabular}

Table 7. Complications with the Clavien-Dindo classification

\begin{tabular}{lcccc}
\hline Clavien-Dindo & $\begin{array}{c}\text { Stage 1 } \\
\mathbf{n = 2 2}\end{array}$ & $\begin{array}{c}\text { Stage 2 } \\
\mathbf{n = 3 7}\end{array}$ & $\begin{array}{c}\text { Stage 3 } \\
\mathbf{n}=\mathbf{5 6}\end{array}$ & $\mathbf{p}$ \\
\hline I & 2 & $7(18.92)$ & $15(26.79)$ & 0.210 \\
II & - & $6(16.22)$ & $16(28.57)$ & 0.013 \\
III a & 2 & $6(16.22)$ & $12(21.43)$ & 0.422 \\
IV b & 1 & $5(13.51)$ & $5(8.93)$ & 0.513 \\
IV b & 2 & $5(13.51)$ & $5(8.93)$ & 0.758 \\
V & 2 & - & $1(1.79)$ & 0.092 \\
\hline
\end{tabular}

to have better results than low-volume centers in other highly complex types of surgery (heart, pancreatic, pulmonary, esophagectomies, and trauma surgery) ${ }^{21-23}$, in the case of OLT, the results have been inconsistent. Edwards et al. ${ }^{6}$ and Axelrod et al..$^{7}$ early studies show that patients at high-volume centers have lower operative mortality after OLT. Edwards et al. ${ }^{6}$ analyzed all OLTs performed in the USA from 1992 to 1994 (more than 7000 patients) and observed better results at high-volume centers in the pre-MELD era. Axelrod et al. ${ }^{7}$, using the USA transplantation registry database, reported in 2004 a statistically significant higher risk of death at centers with low volumes of OLT. Later studies by Northup et al. ${ }^{11}$, Tracy et al. ${ }^{24}$, and Reese et al. ${ }^{25}$ examined these same points after the appearance of MELD and failed to find a direct relationship between the volume of procedures and 1-year survival. It would not appear that the difference in OLT outcomes reported in these studies prior and after MELD is due to lack of experience at the centers. Although OLT outcomes have improved over time all over the world, these studies analyze low- and high-volume centers at the same period. For each epoch, in the USA and Europe, there has been a minimum survival at 1,3 , and 5 years required to be able to perform this type of procedure. 


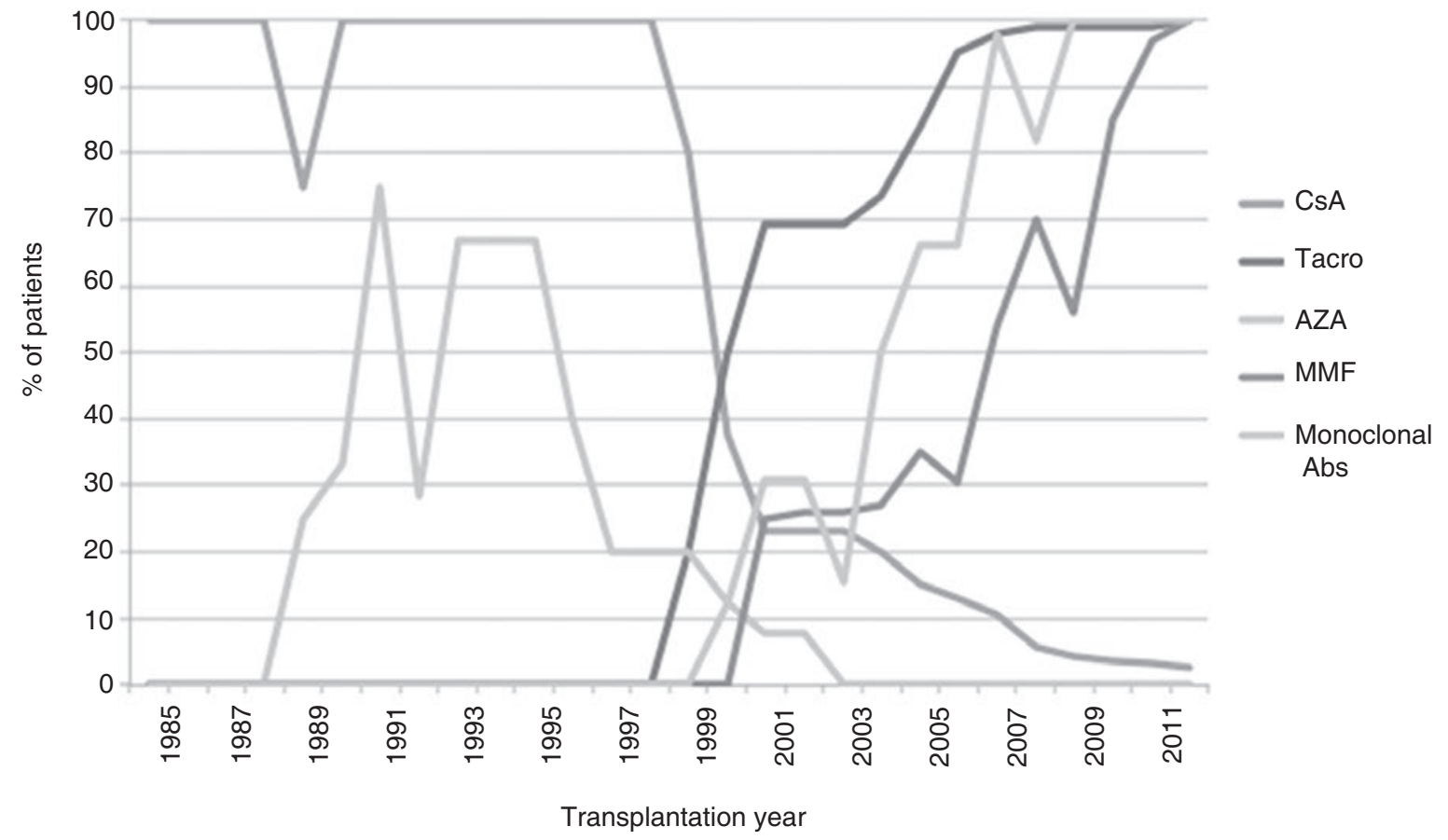

Figure 1. Immunosuppression used in INCMNSZ patients' Orthotopic liver transplantation from 1985 to 2012. Monoclonal Abs: anti-CD25 monoclonal antibodies; AZA: azathioprine; CsA: cyclosporine; MMF: mycophenolate mofetil; Tacro: tacrolimus

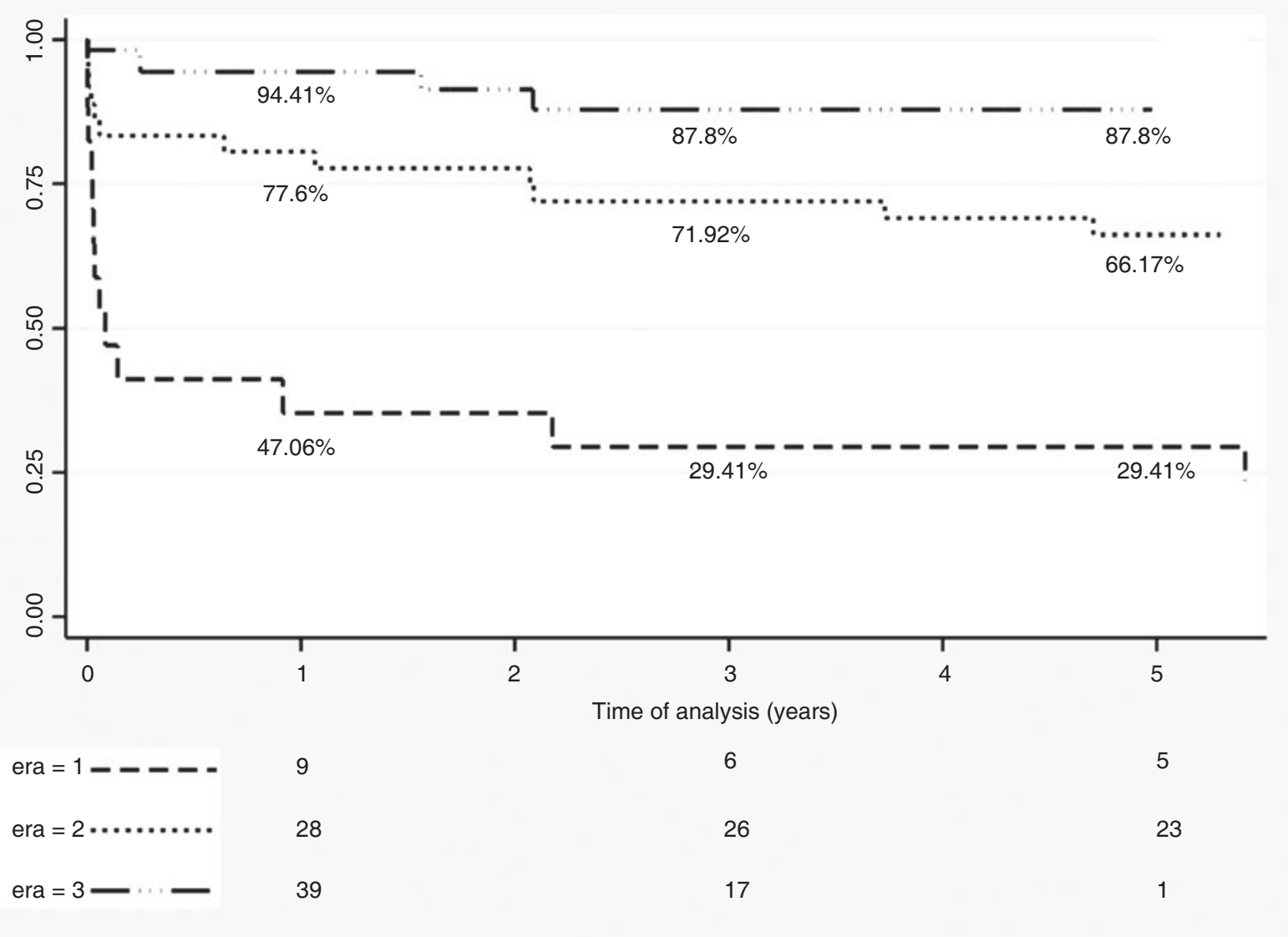

Figure 2. Orthotopic liver transplantation survival divided by stages. 
Table 8. Stage 3 donors clinical and demographic characteristics

\begin{tabular}{|c|c|}
\hline Donors: 55 & $\mathrm{n} /$ mean $(\% / \min -\max$ \\
\hline Age (years) & $27.7(10-64)$ \\
\hline Female & $21(38.2)$ \\
\hline Male & $34(61.8)$ \\
\hline Weight (kg) & $68(40-90)$ \\
\hline Height (cm) & $165(136-185)$ \\
\hline BMI $\left(\mathrm{kg} / \mathrm{m}^{2}\right)$ & $24.6(18.4-35.6)$ \\
\hline \multicolumn{2}{|l|}{ Cause of death } \\
\hline TBI & $35(63.6)$ \\
\hline Stroke & $14(25.5)$ \\
\hline CNS tumor & $4(7.3)$ \\
\hline Other & $2(3.6)$ \\
\hline \multicolumn{2}{|l|}{ Use of amines } \\
\hline Yes & $51(92.7)$ \\
\hline No & $4(7.3)$ \\
\hline \multicolumn{2}{|l|}{ Biopsy } \\
\hline Normal & $36(65.5)$ \\
\hline Grade I steatosis & $19(34.5)$ \\
\hline $\mathrm{SBP}(\mathrm{mmHg})$ & $106(60-80)$ \\
\hline $\mathrm{DBP}(\mathrm{mmHg})$ & $62(30-110)$ \\
\hline $\mathrm{Hb}(\mathrm{g} / \mathrm{dL})$ & $11.7(6.4-18.7)$ \\
\hline Creatinine (mg/dL) & $1.02(0.3-2.6)$ \\
\hline $\mathrm{Na}^{+}(\mathrm{mEq} / \mathrm{dL})$ & $150.9(131-177)$ \\
\hline Total bilirubin (mg/dL) & $0.74(0.1-3.1)$ \\
\hline Direct bilirubin (mg/dL) & $0.28(0-2.4)$ \\
\hline AST (U/L) & $69.7(12-245)$ \\
\hline $\operatorname{ALT}(\mathrm{U} / \mathrm{L})$ & $48(10-210)$ \\
\hline Alkaline phosphatase (U/L) & $76(24-257)$ \\
\hline GGT (U/L) & $29.1(8-145)$ \\
\hline INR & $1.3(0.8-3.2)$ \\
\hline
\end{tabular}

ALT: alanine aminotransferase; AST: aspartate aminotransferase; BMI: body mass index; CNS: central nervous system; DBP: diastolic blood pressure;

GGT: gamma-glutamyltranspeptidase; Hb: hemoglobin; INR: international normalized ratio; SBP: systolic blood pressure; TBI: traumatic brain injury.

In our center, at Stage 3, even with $<20$ transplantations performed per year, outcomes are excellent both in terms of mortality (3.5\%) and 1- and 5-year survival (94.4\% and $87.8 \%$, respectively). In addition, the use of MELD started in 2008, and Stage 3 transplant receivers were, therefore, more seriously ill than those at Stage 2, although the difference was not statistically significant. Even when at Stage 2, there was also an OLT multidisciplinary group available, mortality in that period was $21.6 \%$, which is not negligible and, interestingly, a total of 10 OLTs per year were never reached. To the best of our knowledge, there is no study that mentions which is the minimum number of transplantations that have to be performed per year in a center. In our experience, when comparing Stage 2 with Stage 3, it would appear that performing $<10$ OLTs might affect the results. At Stage 2, no improvement was observed in 8 years in spite of the global experience acquired. At Stage 3, the surgical team was changed and, therefore, we cannot assume that the results improved due to higher global experience. In addition to the change in the surgical team, the other factor we considered to be important for the results is the fact that, since 2008, more than 10 OLTs have been performed per year. We believe this information is valuable since, in Mexico, in the year 2012, only 4 centers in the entire country performed 10 or more OLTs per year, even when there are 62 centers authorized to perform this procedure ${ }^{26}$. Unfortunately, reporting the results is not mandatory in our country, and this hinders adequate quality control at each center, in addition to renewable and non-renewable resources (organs) being used in groups lacking a minimum indispensable of survival at 1,3 , and 5 years, as well as low perioperative mortality. The few reports on Mexican centers' results in national journals show that, in most cases, they are far below of what is desired by international standards, and all these hospitals normally perform $<10$ OLTs per year.

This is the first time that, with a study of a Mexican OLT center, being a medium- or high-volume center has been shown not to be necessary to obtain excellent results, but it has also been suggested that performing $<10$ OLTs a year can make for the results to be considerably inferior and even unacceptable. Should this be confirmed, there would be a sufficiently important reason to change the strategy of responsible authorities in our country and to increase the number of centers to perform more transplantation and centralize this complex procedure in groups that perform at least 10 transplantations per year.

Once a group acquires sufficient experience, probably performing $<10$ transplantations per year will not affect the results at the beginning but, eventually, if this procedure becomes very sporadic, the probabilities of error in one or several steps of this complex surgery do increase. In our experience, the number of transplantations per year has increased. In our center, 
this increase is multifactorial: On one hand, the number of surgeons, anesthesiologists, and hepatologists was increased, and on the other, the number of organ offerings got higher.

In conclusion, OLT in our institute is a reality. Since 2008, the results have been excellent, even better than those in some centers from the USA and Europe, in spite of not being a medium- or high-volume center. It would appear that the minimum number of OLTs is 10 per year to be able to achieve similar results to those reported at the international level.

\section{Acknowledgments}

We would like to specially acknowledge all those who significantly contributed to the INCMNSZ OLT program in the past: Dr. Héctor Orozco Zepeda', Dr. Héctor S. Diliz, Dr. Carlos Chan Núñez, Dr. Federico Chavez Peón ${ }^{\dagger}$, Dr. Víctor Acosta, Dr. Guillermo Castorena, Dr. Luis Guevara-González ${ }^{\dagger}$, Dr. David Kershenobich, and Dr. Marco A. Olivera, as well as the INCMNSZ directors, who supported the program since its initiation: Dr. Manuel Campuzano, Dr. Donato Alarcón ${ }^{\dagger}$, Dr. Fernando Gabilondo, and Dr. David Kershenobich.

\section{References}

1. Vilatoba M, Eckhoff DE, Contreras JL. Selección del receptor para trasplante hepático. Rev Invest Clin. 2005;57:244-51.

2. Birkmeyer JD, Siewers AE, Finlayson EVA, et al. Hospital volume and surgical mortality in the United States. N Engl J Med. 2002;346:1128-37.

3. Halm EA, Lee C, Chassin MR. Is volume related to outcome in health care? A systematic review and methodologic critique of literature. Ann Intern Med. 2002;137:511-20.

4. Reames BN, Ghaferi AA, Birkmeyer JD, et al. Hospital volume and operative mortality in the modern era. Ann Surg. 2014;260:244-51.

5. Hosenpud JD, Breen TJ, Edwards EB, et al. The effect of transplant center volume on cardiac transplant outcome. A report of the United Network for Organ Sharing Scientific Registry JAMA. 1994;271:1844-9.
6. Edwards EB, Roberts JP, McBride MA, et al. The effect of the volume of procedures at transplantation centers on mortality after liver transplantation. N Engl J Med. 1999;341:2049-53.

7. Axelrod D, Guidinger M, McCulloug K, et al. Association of center volume with outcome after liver and kidney transplantation. Am J Transpl. 2004;4:920-7.

8. Ahmad J, Bryce C, Cacciarelli T, et al. Differences in access to liver transplantation: Disease severity, waiting time, and transplantation center volume. Ann Intern Med. 2007;146:707-13.

9. Ozhathil D, Fu Li Y, Smith J, et al. Impact of center volume on outcomes of increased-risk liver transplants. Liver Transpl. 2011;17:1191-9.

10. Scarborough J, Pietrobon R, Tuttle-Newhall J, et al. Relationship between provider volume and outcomes for orthotopic liver transplantation. $\mathrm{J}$ Gastrointest Surg. 2008;12:1527-33.

11. Northup P, Pruett T, Stukenborg G, et al. Survival after liver transplantation does not correlate with transplant center case volume in the MELD era. Am J Transpl. 2006;6:2455-62.

12. Secretaría de Salud, Salud: México 2006 Información para la rendición de cuentas, 2007. (Septiembre 2017). http://www.salud.gob.mx/unidades/evaluacion/saludmex2006/SM06.pdf

13. Duro-García V, Niño-Murcia A. Report 2013. Latin America Transplantation. 2013;1:93.

14. Feng S, Goodrich NP, Bragg-Gresham JL, et al. Characteristics associated with liver graft failure: The concept of a donor risk index. Am J Transpl. 2006;6:783-90.

15. Diliz H, Orozco H, Kershenobich D, et al. Liver transplantation in Mexico. Report of the first successful case. Rev Gastroenterol Mex. 1991;56:33-8.

16. Varela-Fascinetto G, Hernández-Plata JA, Nieto-Zermeño J, et al. Programa de trasplante hepático pediátrico en el Hospital Infantil de México Federico Gómez. Rev Invest Clin. 2011;63(Suppl 1):57-61.

17. Hernández-Domínguez JM, Holm-Corzo A, Santos-Caballero M, et al. Experience in liver transplantation (1996-2011) at the UMAE, General Hospital Gaudencio Gonzalez Garza, National Medical Center La Raza, Mexican Institute of Social Security, Mexico City, D.F. Rev Invest Clin. 2011;63(Suppl 1):62-6.

18. Cisneros-Garza LE, López-Hernández PA, Muñoz-Ramírez MR, et al. Trasplante hepático en la Unidad Médica de Alta Especialidad Num. 25, IMSS Monterrey. Rev Invest Clin. 2011;63(Suppl 1):69-72.

19. Rodríguez-Montalvo C, Tijerina-Gómez L, Flores-Villalba E, et al. Doce años de trasplante hepático continuo en el Hospital San José-Tec de Monterrey. Rev Invest Clin. 2011;63(Suppl 1):73-8.

20. Pérez-Rodríguez E, Muñoz-Espinosa LE, Zapata-Chavira $H$, et al. Trasplante hepático ortotópico. Experiencia en el Hospital Universitario de Monterrey, N.L. Rev Invest Clin. 2011;63(Suppl 1):79-84.

21. Bach PB, Cramer LD, Schrag D, et al. The influence of hospital volume on survival after resection for lung cancer. N Engl J Med. 2001;345:181-8.

22. Birmeyer JD, Siewers AE, Finalyson EV, et al. Hospital volume and surgical mortality in the United States. N Engl J Med. 2002;346:1128-37.

23. Rathore SS, Epstein AJ, Volpp KG, et al. Hospital coronary artery bypass graft surgery volume and patient mortality, 1998-2000. Ann Surg. 2004;239:110-7.

24. Tracy E, Bennett $\mathrm{K}$, Aviki E, et al. Temporal trends in liver transplant centre volume in the USA. HPB. 2009;11:414-21.

25. Reese $\mathrm{P}, \mathrm{Yeh} \mathrm{H}$, Thomasson $\mathrm{A}$, et al. Transplant center volume and outcomes after liver retransplantation. Am J Transpl. 2009;9:309-17.

26. CENATRA, Reporte Nacional 2012 de la Donación y Trasplantes, 2012. (Septiembre 2017). http://cenatra.salud.gob.mx/descargas/contenido/ trasplante/informe_anual_2014.pdf 